\title{
What are the effects of control
} of mosquitoes and other nematoceran Diptera using the microbial agent Bacillus thuringiensis israelensis (Bti) on aquatic and terrestrial ecosystems? A systematic review protocol

\author{
Magnus Land ${ }^{1 *}\left(\mathbb{0}\right.$, Mirco Bundschuh²,5, Richard J. Hopkins ${ }^{3}$, Brigitte Poulin ${ }^{4}$ and Brendan G. McKie ${ }^{5}$
}

\begin{abstract}
Background: The bacterium Bacillus thuringiensis serovar israelensis (Bti) is used in many countries as a biological larvicide to control dipteran insects of the suborder Nematocera, especially mosquitoes and black flies. Bti is generally accepted to be target-specific and efficient, with low potential for development of resistance among the target species. However, even though Bti may have minimal direct effects on non-target organisms, it might potentially be associated with knock-on effects on food webs and other ecosystem properties, including biodiversity and ecosystem functioning. Evidence from previous research is mixed, with some finding no evidence for indirect effects on biodiversity and ecosystem-level properties, but others indicating that such effects are possible. The fact that many studies have been conducted by organisations coordinating the control programs, and that many of those studies have been published outside peer reviewed scientific journals, highlights the challenges for decision makers and others to assess the results of the existing studies. In this protocol we outline how we aim to systematically and transparently synthesise all available evidence in a forthcoming systematic review.

Methods: We will use six bibliographic databases/platforms and the online search engines Google and Google Scholar in searches for literature. Searches will also be made on specialist websites. We will screen the search results for eligibility in stage one based on title and abstract, and in stage two based on the full text of the material. At stage one, after testing and clarifying the eligibility criteria, two reviewers will split and single screen the search results. At stage two the articles will be screened independently by two reviewers. We have developed a preliminary critical appraisal tool that will be used as basis for assessing study validity. Each study will be critically appraised independently by two reviewers. Disagreements will be reconciled through discussions seeking to reach consensus. It is unclear whether a quantitative synthesis based on meta-analysis will be feasible. A narrative synthesis will include descriptive statistics outlining the evidence base in terms of bibliographic information and study metadata. A narrative synthesis table in the form of an Excel spreadsheet will be provided.
\end{abstract}

Keywords: Culicidae, Simuliidae, Biodiversity, Food web, Biocontrol, Species interactions, Insecticide, Larvicide, Biopesticide, Indirect impacts

\footnotetext{
*Correspondence: magnus.land@formas.se

${ }^{1}$ The Swedish Research Council for Environment, Agricultural Sciences and Spatial Planning (Formas), Box 1206, 11182 Stockholm, Sweden Full list of author information is available at the end of the article
} 


\section{Background}

The bacterium Bacillus thuringiensis serovar israelensis (Bti) was isolated from a stagnant pond located in the Negev in south Israel in 1976, and was proven in laboratory experiments and field research to be a highly selective control agent for biting insects from the dipteran (true fly) suborder Nematocera, especially mosquitoes (Culicidae) and blackflies (Simuliidae) (reviewed in Boisvert and Boisvert [1]). Bti produces crystal aggregations containing multiple toxins that disrupt the gut wall of organisms having an alkaline environment in their digestive tracts, as is typical of Nematocera [2-4]. Today, Bti is commercially produced in various formulations for use all over the world. Bti typically causes 90-100\% mortality to target organism larvae, with generally limited or no documented direct impacts on other aquatic and terrestrial species $[1,5,6]$, especially compared with alternative chemical controls [7]. Nontarget organisms (NTO) showing some susceptibility to Bti are, like mosquitoes, most commonly members of the Diptera suborder Nematocera. In particular, nonbiting midges (Chironomidae) may be susceptible to Bti [8-10], albeit at doses more than ten times greater than those recommended for mosquito control [11]. Nevertheless, some evidence for direct impacts of Bti on NTOs exists $[12,13]$, including on vertebrate species [14].

Even when Bti has minimal direct effects on NTOs, it may potentially be associated with knock-on effects on other ecosystem properties, including biodiversity and ecosystem functioning. Such indirect effects occur when the direct effects of a control agent on the density and/ or behaviour of one or more organisms (target or NTO) result in changes in the properties of food webs (e.g., Newman and Clements [15]). This might be reflected in changes in food web structure, e.g. number of trophic levels or number and type of species within trophic levels, and/or function, e.g. rates and outcomes of nutrient transformations and biomass production and consumption within the food web [16]. For example, a reduction of adult mosquito biomass of $90-100 \%$ following Bti application may remove an important food source for terrestrial organisms. Indeed, evidence from a longerterm study indicates that reductions in the biomass of emerging nematoceran dipterans (mosquitoes and chironomids) from wetlands treated with Bti alters the diet of birds, in turn reducing their breeding success [17]. Reductions in abundances of biting insects might also relieve vertebrate herbivores or predators from the negative effects of blood loss and the parasites that blood feeding insects often spread $[18,19]$, potentially altering the impact of these species on the plant and animal communities these vertebrates consume.
In Sweden, Bti has been applied since 2002 in the lower Dalälven River area, to control mass outbreaks of the floodplain mosquito Aedes (Ochlerotatus) sticticus Meigen [6]. Mass emergence events of this species have been extreme (e.g. 60,000 individuals were caught in one trap during one night in 2000), seriously compromising the quality of life for inhabitants of the region [6, 20]. Bti, in the form of the commercially available granular formulation VectoBac $\mathrm{G}^{\circledR}$ (Valent BioScience, USA) has been applied in almost all years since 2002, excepting 2004, 2013 and 2017 (http://www.mygg.se). During 2002-2011, the number of applications ranged from 0 to 4 times per year during May-August, at an average dose of 13-15 kg/ ha, with treated areas ranging from less than 100 to more than 3500 ha [6]. This control program has been highly effective at reducing abundances of flying A. stictacus, evident not only in individual mosquito outbreak years [6], but also possibly in the long-term trend for declining densities during outbreaks since the early 2000s (http:// www.mygg.se). Ongoing monitoring of impacts on NTOs in the lower Dalälven has uncovered little evidence of negative outcomes for Chironomidae [21]. Assessment of indirect ecological effects in the lower Dalälven are scarce. Native bacteria (Bacillus cerus group) abundances appear little affected [22]. However, increases in the abundance of Bti itself [22] and the densities and taxonomic richness of heterotrophic protozoans (4.5 times higher in wetland areas treated with Bti [23]) point towards potential changes in the microbiota of treated wetlands. This, together with changes in beetle assemblages [24] and the niche-breadth of ground-based food webs (quantified based on isotopic biomarkers, McKie et al. [25]) indicate the potential for repeated application of Bti to alter food-web properties, although it is not clear whether any of these changes should be regarded as deleterious. Finally, the marked reduction in abundances of flying $A$. sticticus adults could have wider consequences for other organism groups, which might be either positive (e.g. reduced harassment and blood-feeding on vertebrates) or negative (a reduction in food for predators), but these have not been investigated.

The Swedish Environmental Protection Agency (Swedish EPA) judges the risk of unwanted ecological impacts of large-scale and repeated Bti treatments to still be unclear and does not find any legal ground for permitting Bti treatments in the Natura 2000-designated areas of the lower Dalälven catchment. However, the Swedish EPA has returned the decision regarding whether permission should be granted to the Swedish government, which takes account of the great demand for Bti treatment in some of these areas [26]. The EPA has also expressed a need for a synthesis of the available evidence for ecological impacts of mosquito control with 
Bti. To refine the review question and design a systematic review as balanced and relevant as possible, the Swedish research council Formas arranged a stakeholder meeting where representatives from the Swedish EPA, county administrative boards, municipalities, non-governmental environmental organisations, and mosquito control associations discussed the significance of the question, potential sources of evidence, study inclusion criteria, and study quality aspects, among other things. After that meeting, the stakeholders were given an opportunity to review an earlier version of this protocol. A complete list of organisations represented at the meeting can be found in Additional file 1.

Although the initial motivation for this review arose from the specific situation in Sweden, evidence from all over the world will be compiled. Accordingly, the findings of the review are expected to have broad relevance to all regions of the world where biological control of blood feeding Nematocera is undertaken. The forthcoming systematic review is planned to follow the guidelines developed by Collaboration for Environmental Evidence [27].

\section{Objective of the review}

The objective of the review is to evaluate the evidence for effects of Bti treatments for control of nematoceran Diptera (e.g. mosquitoes and black flies) on terrestrial and aquatic ecosystems. Here we are not primarily concerned with the direct effects of Bti cry toxins on target organisms, which although relevant for understanding complex changes at the ecosystem level, are reasonably well understood. Rather, we are primarily interested in examples where not only the intended effects of control on target organisms are both achieved and empirically reported, but also unintended consequences on other ecosystem properties are documented. Such unintended effects might include changes in the structure (biodiversity, trophic levels, functional group composition), resource base (e.g. relative importance of different plant types and/or detritus) and functioning (changed ecosystem processes including those underpinning biogeochemical cycles) of food webs. Accordingly, studies that only report changes in the abundance of target organisms without data on changes in other ecosystem properties are not considered relevant for our review. In contrast, studies documenting direct effects of Bti on non-target organisms, which are generally poorly understood in the field, will be considered relevant as they investigate wider ecosystem consequences of Bti use, beyond target organism impacts.

Effects on ecosystems can and have been measured in several different ways (see below). In principle, all outcomes related to ecosystem structure, functioning or ecosystem processes are of relevance to this review. Although this procedure reduces the possibility of combining all studies in a single meta-analysis, the planned systematic review will provide a transparent and reproducible overview on study outcomes related to the primary question. The systematic review is built on the following key elements:

\section{Subject: $\quad$ Aquatic and terrestrial ecosystems \\ Exposure: Bti treatments for control of mosquitoes and other nematoceran Diptera \\ Comparator: (1) Reference ecosystems not exposed to Bti or any other Nematoceran control agent/intervention. (2) Reference eco- systems not exposed to Bti but exposed to other Nematoceran control agents/ interventions. \\ Outcome: Outcomes related to food web structure and function}

These key elements are further defined and delimited in the subsection on study eligibility criteria. Secondary questions are related to potential effect modifiers and include: (1) Are ecosystems more affected by long-term and repeated Bti treatments? (2) Is there a clear doseresponse relationship? (3) Do landscape characteristics (e.g. in terms of floodplain characteristics, vegetation type, species composition etc.) affect the type or size of effects?

\section{Methods \\ Searching for articles}

Searches will be made in the bibliographic databases and platforms listed in Table 1. The selection of these is governed by subscriptions available to the authors. The search string used will be adapted to valid syntax in each database, but in principle it will be based on the following search string:

(nematocera* OR midge* OR diptera* OR mosquito* OR vector" OR larv" OR "black fly" OR "black flies" OR biting OR chironom* OR culicid* OR simuliid* OR anopheles OR aedes OR ochlerotatus OR culex OR culiseta OR limatus OR uranotaenia OR psorophora OR mansonia OR armigeres OR trichoprospon OR coquillettidia OR tripteroides) AND (bti OR israelensis OR vecto-

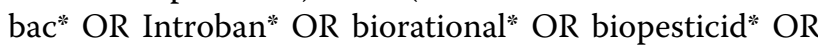
biolarvicid*).

The asterisk (*) is a wildcard representing any number of characters. An evaluation of the search string is shown in Additional file 2. No constraints regarding time, document type, or language will be applied when searching for 
Table 1 Bibliographic databases used for searching

\begin{tabular}{|c|c|c|}
\hline Database/platform & Searched field & Publisher and URL \\
\hline Web of Science ${ }^{a}$ & Topic & Clarivate Analytics, https://clarivate.com/products/web-of-science/ \\
\hline Scopus & Title, abstract and keywords & Elsevier, https://www.scopus.com/ \\
\hline ProQuest Natural Science Collection ${ }^{\mathrm{b}}$ & Abstract & Proquest, https://www.proquest.com/ \\
\hline CAB Abstracts & $\begin{array}{l}\text { Abstract, title, original title, broad terms, } \\
\text { heading words, identifiers, cabicodes }\end{array}$ & Ovid, http://www.ovid.com/site/catalog/databases/31.jsp \\
\hline Academic search premier & Abstract or author-supplied abstract & $\begin{array}{l}\text { EBSCO, https://www.ebsco.com/products/research-databases/ } \\
\text { academic-search-premier }\end{array}$ \\
\hline Directory of Open Access Journals ${ }^{c}$ & All fields & Independent, https://doaj.org/ \\
\hline \multicolumn{3}{|c|}{ a Including Web of Science ${ }^{\mathrm{TM}}$ Core Collection, KCI-Korean Journal Database, MEDLINE, Russian Science Citation Index, and SciELO Citation Index } \\
\hline \multicolumn{3}{|c|}{$\begin{array}{l}\text { b Including AGRICOLA, Agricultural Science database, Aquatic Sciences and Fisheries Abstracts (ASFA), Biological Science database, Biological Science index, Earth, } \\
\text { atmosphere \& Aquatic Science database, Environmental Science database, Environmental Science index, MEDLINE, Meteorological \& Geoastrophysical Abstracts, and } \\
\text { TOXLINE }\end{array}$} \\
\hline
\end{tabular}

literature. At a later stage some languages may however be excluded due to limitations in translation resources.

Literature will also be searched for using the internet search engines Google and Google Scholar in advanced search mode. For these search engines the simplified search strings below will be used.

Mosquito AND effect AND (Bti OR israelensis OR vectobac).

"Black fly" AND effect AND (Bti OR israelensis OR vectobac).

Thesis AND Bti AND mosquito AND (MSc OR PhD).

Searches in Google Scholar will be performed through Publish or Perish [28], and for each search string the first 500 articles will be screened. Search results in Google will be restricted to pdf documents, and for each search string the first 100 will be screened. The number of search results from Google that will be screened is lower because of resource constraints. The same search strings translated to Swedish, German and French will also be used. Screening of search results from non-English language searches will also be limited to the first 100 hits for each search string. We acknowledge that the simplified search strings may favour studies on mosquito control over studies on control of other biting insects. On the other hand, given the limited possibilities to perform sensitive yet reasonably specific searches using Google and Google Scholar, it is not realistic to expect these searches to be comprehensive.

Websites of relevant specialist organisations (listed by region below) will also be searched. In this case the search strings will be website specific (all search strings will be reported in the systematic review), but typically the term Bti will be included. Also, non-automated searches on the organisations' publications page will be performed. If no reports are found on the website of an organisation that presumably does have relevant information, an enquiry will be sent to the appropriate person or the organisation's official email address.

\section{Europe}

- European Mosquito Control Association, http:// www.emca-online.eu/

- KABS e.V. (Kommunale Aktionsgemeinschaft zur Bekämpfung der Schnakenplage), https://www.kabse v.de/

- Verein Biologische Gelsenregulierung entlang Thaya und March, http://mta-gelsen.at/

- Biologisk myggkontroll, http://mygg.se/

- EID Méditerranée, http://www.eid-med.org/

- EID Atlantique, https://www.eidatlantique.eu/

- EID Rhône-Alpes, https://www.eid-rhonealpes.com/

- Brigade Verte, https://www.brigade-verte.fr/demou stication

- The Netherlands Institute of Ecology, https://nioo. knaw.nl/en

- Innovative Vector Control Consortium, http://www. ivcc.com/

- Swedish Environmental Protection Agency, https:// www.naturvardsverket.se/

- Federal Agency for Nature Conservation (BfN), https ://www.bfn.de/en.html

\section{North America}

- American Mosquito Control Association, https:// www.mosquito.org/

- Northwest Mosquito and Vector Control Association, https://nwmvca.org/ 
- North Central Mosquito Control Association, http:// north-central-mosquito.org/WPSite/

- Northeastern Mosquito Control Association, http:// www.nmca.org/

- West Central Mosquito \& Vector Control Association, https://www.westcentralmosquitoandvector. org/

- Mid-Atlantic Mosquito Control Association, https:// www.mamca.org/

- Mosquito and Vector Control Association, of California https://www.mvcac.org/

- Florida Mosquito Control Association, https://www. floridamosquito.org/

- Canadian Entomological Society, https://esc-sec.ca

- United States Environmental Protection Agency, https://www.epa.gov/

- Environment and Climate Change Canada, https ://www.canada.ca/en/environment-climate-chang e.html

\section{Rest of the world}

- Asian society for Vector Ecology and Mosquito control, https://www.asiansvemc.org/

- The Society for Vector Ecology (SOVE) Indian Region, http://www.soveindia.org/

- Pan-African Mosquito Control Association, https:// www.pamca.org/

- Fiocruz, https://portal.fiocruz.br/

- Mosquito Control Association of Australia, https:// mcaa.org.au/

In addition, calls for literature will be announced within networks of the review team members.

The comprehensiveness of the searches will be tested by cross-checking the search results with (1) a list of benchmark papers that the review team a priori think should be found by the searches (see Additional file 3), and (2) bibliographies in relevant review articles found during searches. Preliminary searches in the bibliographic databases showed that all but three of the items in Additional file 3 were found. If any of the missing items or if any relevant item in the checked review bibliographies is not found in the final searches including all sources, the search strategy may be changed. Any such changes will be reported in the systematic review.

\section{Article screening and study eligibility criteria Screening process}

Search results will be exported to EndNote X9 in which removal of duplicates will be conducted. All unique articles will then be exported to Eppi Reviewer 4.0 where screening on relevance will take place in two stages. At stage one the screening will be based on title and abstract and at stage two it will be based on full text. To test the eligibility criteria, 557 articles found in preliminary searches were screened by multiple authors of this protocol independently. Following an analysis of all disagreements and amending the preliminary eligibility criteria with necessary clarifications, the authors reached consensus on the interpretation of the criteria. We are now confident that the search results can be split between two reviewers and screened consistently by following the procedure outlined below.

The reviewers will be inclusive in their judgements, i.e., if doubtful the article should be included for full text screening. However, to avoid a need to download an unnecessary excessive amount of full text articles the reviewers will have three options during screening at stage one: (1) include, (2) exclude, and (3) probably exclude. All articles coded with option 3 will then be screened by all authors, after which a consensus decision will be made. This is a precaution to minimise the risk that one reviewer excludes an article on false grounds. All articles included after this process will at stage two be screened independently by two reviewers, and any disagreements will be reconciled through discussions among all reviewers (authors of this article). Reviewers will be allowed to assess the relevance of their own work and decide on inclusion or exclusion during the screening process. However, they will not be allowed to assess the validity of their own work (see "Study validity assessment" section). At stage two excluded articles will be coded with a reason for exclusion.

\section{Eligibility criteria}

In evaluating the whole ecosystem effects of Bti, we prioritise contributions where Bti itself is the primary agent of change in densities of target organisms. Although effects of a certain change in the food web (e.g. reduction in mosquito biomass) may be the same regardless of what factor caused the change in the food web (e.g. Bti or some other control method), it should not be ruled out that some indirect effects caused by Bti could be specific to the nature of the Bti treatment itself. For example, it has been suggested that the corn-based granulate carrier of Bti in the product VectoBac $\mathrm{G}^{\circledR}$ may cause changes in the available carbon source for some organisms, potentially leading to ecosystem effects [25]. Furthermore, since Bti is the most commonly used larvicide worldwide and the only one approved in the European Union, this specific control method needs to be evaluated. However, where such comparisons exist, we will compare the effects of Bti treatments with those associated with other methods. Accordingly, two different comparators will be eligible for 
inclusion, one with no midge control and one with midge control by other means. There will be no geographic limitation. Even though our focus is on temperate and Nordic systems, ecosystems are complex and insights in for example tropical systems can inform decision making in other ecosystems when posting more general questions as we do here (indirect effects). The following criteria will be used when assessing relevance and deciding on inclusion or exclusion of studies.

- Subject: Aquatic and terrestrial ecosystems.

- Exposure: Bti treatments for control of mosquitoes, black flies or other nuisance nematoceran (Diptera) or for Bti effect assessment. All forms of Bti products (granular, liquid, sterilised, non-sterilised etc.) and application techniques (ground-based, air-borne etc.) will be included.

- Comparator (1) Reference ecosystems not exposed to Bti or any other Nematoceran control agent/intervention. (2) Reference ecosystems not exposed to Bti but exposed to other Nematoceran control agents/ interventions.

- Types of outcome: Outcomes related to food web structure and function, e.g. changed abundance of any non-target species (expected to be sensitive or not sensitive to Bti cry toxins), species richness, species composition, species diversity indices, species traits/feeding groups, reproduction success, indicators of changed food sources, changed ecosystem processes (e.g. plant productivity), eutrophication, persistence of applied Bti (not including short-term persistence in effect against target species) and transfer of Bti genetic material etc.

- Types of study Field-based studies or mesocosm studies using field-sourced communities or laboratory studies including quantification of ecological interactions, using before-after (BA), control-impact (CI), before-after control-impact (BACI), or randomised control trial (RCT) study designs.

- Eligible languages: English, German, French, Swedish, Spanish.

An earlier version of the eligibility criteria was tested by all reviewers on a subset of articles captured in preliminary searches, after which some clarifications were made. For example, vector-borne pathogens are part of ecosystems, and studies documenting changes in abundances of such pathogens in aquatic or terrestrial food webs may be eligible. However, changes in incidences of pathogens among human populations are beyond the scope of the review question. A list of all articles excluded at full text screening, with reasons for exclusion, will be provided in the systematic review.

\section{Study validity assessment}

Critical appraisal of relevant studies will include assessment of both internal and external validity.

\section{Internal validity}

The internal validity assessment will be based on (1) study design (2) data quality based on e.g. sampling strategy, detection methods, and level of taxonomic identification, (3) sources of bias, and (4) statistical analysis.

Based on a scoping study (unpublished) we believe that most studies will have a BA or CI design, but some studies with a BACI design will also be found. We do not anticipate finding any RCT studies. Rating of the studies will not be based on the study design alone, but we do recognise the susceptibility to different sources of bias depends on the study designs.

Details regarding sampling strategy and detection methods that will be considered depend on the type of outcome being measured in each study. However, for most outcomes one key challenge is that the studied systems are often highly heterogenous both in space and time, especially periodically flooded wetlands. It is therefore important to consider the ability of each study to account for such heterogeneity and provide results that are representative for the studied system. Key parameters that will be recorded include study duration, size of study area, spatial and temporal sampling density, level and method of taxonomic identification, method for quantifying Bti spores in the field, and number of true replicates (e.g. spatially independent sampling units).

Within the primary review question addressed here we expect the main sources of bias to include selection bias, performance bias, detection bias, and reporting bias. In this case, risk of selection bias may be high when treatment and control areas were not selected randomly. However, given the potentially large degree of heterogeneity in many target species habitats, randomisation in allocation of treatment and control areas requires a relatively large sample size (high number of replicates) to balance all heterogeneities and confounding factors between two independent groups of treatment areas and control areas, respectively. If the sample size is low, it may not be unlikely that all control areas by chance are characterised by, for example, a larger proportion of open water compared to the exposure areas. The risk for this kind of selection bias may be lower in studies where comparable study areas are matched in pairs, and where treatment allocation is randomized within each pair. As guidance for assessment of selection bias we will use Table 2. Performance bias may occur when study groups are managed differently in some way. To investigate the research question reviewed here, no particular management of 
Table 2 Guidance for assessing risk of selection bias at different study designs

\begin{tabular}{|c|c|c|c|}
\hline Study design & Treatment and control areas & $\begin{array}{l}\text { Randomisation } \\
\text { of treatment allocation }\end{array}$ & Risk of selection bias \\
\hline BA & Treatment and control in same area & $\mathrm{N} / \mathrm{A}$ & Low \\
\hline \multirow[t]{6}{*}{$\mathrm{Cl}$} & \multirow{3}{*}{$\begin{array}{l}\text { Independent groups (spatially independent replicated controls and } \\
\text { exposure areas) }\end{array}$} & Yes & Probably low/probably high \\
\hline & & No & High/probably high \\
\hline & & Unclear & Unclear \\
\hline & \multirow[t]{3}{*}{ Matched pairs (one control and one exposure area in each replicate) } & Yes, within pairs & Low \\
\hline & & No & Probably high \\
\hline & & Unclear & Unclear \\
\hline $\mathrm{BACl}$ & Independent groups or matched pairs & Yes or No & Low/probably low \\
\hline
\end{tabular}

Table 3 Guidance for assessing risk of performance bias at different study designs

\begin{tabular}{llll}
\hline Study design & Source of performance bias & Reported or suspected & Risk of performance bias \\
\hline $\mathrm{BA}$ & Confounding factor or time-related trend & High/probably high \\
& & Yes & Low/probably low \\
& & Unclear \\
$\mathrm{Cl}$ and $\mathrm{BACl}$ & Confounding factor or contamination of study groups & Yes & High/probably high \\
& & No & Low/probably low \\
& & Unclear & Unclear \\
& Time-related trend & Yes or No & Low (N/A for Cl) \\
\hline
\end{tabular}

the study subjects is required, as is often the case in for example agricultural studies, meaning that the risk of such performance bias should generally be relatively low.

Of course, other types of confounding factors than those introduced by the researchers or managers may still be present and form a source of performance bias. For example, some areas may be more visited by tourists or more susceptible to extreme weather conditions than others. Ubiquitous time-related trends, and contamination of study groups where treatment and control areas are not isolated from each other may also form sources of performance bias. As guidance for assessment of performance bias we will apply the framework presented in Table 3. It should be stressed that Tables 2 and 3 provide guidelines only, and that deviating assessments can be made for individual studies if justified. Detection bias may occur if different sampling or measurement methods are used for different organism groups in a food web, or if inadequate methods were used in some replicates or environmental conditions. For example, the number of insects collected by a certain device may not only depend on the abundance of the insects but also on the activity of those insects, and the activity of the insects may vary with a range of local and temporary conditions. In such cases, even if the same sampling device is used for all study groups and across all replicates, the efficiency of that sampling device may vary between different environmental settings or times. Finally, reporting bias will be assessed by checking if results for all measured outcomes in individual studies are reported. We will assume that all study designs are equally susceptible to detection bias and reporting bias.

\section{External validity}

External validity, i.e. the degree to which the studies are appropriate or applicable for answering the review question in a particular context, will partly be assessed based on the eligibility criteria during relevance screening. Nevertheless, the eligibility criteria for exposure need further consideration. So far it has only been stated that the relevant exposure scenario is that a Bti treatment for mosquito or black fly control has been applied. However, to be able to reliably conclude that an exposure or intervention lacks non-intentional side-effects, the study should demonstrate that the level of exposure or intervention indeed was sufficient to obtain the intentional effect (in this case a significant decrease in target species abundance). It can be discussed how much lower the target species abundance needs to become as a result of the Bti treatment, but it has been argued that as much as $95 \%$ of the larvae needs to be killed to achieve a significant decrease in the perceived nuisance by people 
[6]. Accordingly, a statistically significant decrease in the abundance of mosquito larvae alone is not enough to evaluate success of mosquito control. It is also difficult to define successful mosquito control efforts by a fixed number that can be applied across all environments, target organism species, and social contexts. For example, container breeding species in residential areas may be harder to control than ground breeding flood mosquitoes, even though both may be equally sensitive to the Bti cry toxins, e.g. under laboratory control trials. This is because in practice it is likely to be more difficult to find and treat all possible breeding sites in a built environment, than to spray large wetlands in areas of low human population density. Furthermore, in many areas a mix of biting Nematocera species are present, and the goal of Bti treatment might be to reduce the abundance of several species simultaneously. Overall, it is difficult to a priori define which (mix of) species should be targeted, and how much the target species abundance must decrease, to make a study externally valid.

Here we will choose a pragmatic approach where we do not exclude any studies based on target nematoceran species or achievement of intentional effect, but where we record these parameters for each study and make a comment on the external validity in a Swedish context. The assessment of external validity will be more focused on the application rate of Bti, which we believe is a key effect modifier (see "Potential effect modifiers/reasons for heterogeneity" section). Application rate is here defined as dose $(\mathrm{kg} / \mathrm{ha})$ per treatment and number of treatments per year. In 2018 the maximum allowed application rate in Sweden was $15 \mathrm{~kg}$ Vectobac $\mathrm{G}^{\circledR} /$ ha per treatment, and 4 treatments/year [29]. The active ingredient in Vectobac $\mathrm{G}^{\circledR}$ is Bacillus thuringiensis subsp. israelensis serotype H-14, strain AM65-52.

\section{Coding for study validity assessment}

Data on key parameters necessary for study validity assessment will be entered in a predesigned data sheet. This data sheet will, together with Tables 2 and 3, constitute a critical appraisal tool to be used in the systematic review. Parameters and allowed optional entries included in the critical appraisal data sheet are shown in Table 4. The completed critical appraisal data sheet will be provided as supplementary information with the systematic review.

Critical appraisal and coding for study validity will be carried out by all reviewers, and each study will be critically appraised by two reviewers. The reviewers will not be allowed to assess the validity of their own work. Disagreements will be reconciled through discussions seeking to reach consensus among all reviewers. If quantitative synthesis is feasible a sensitivity analysis, comparing results with and without exclusion of studies with low validity, may be performed.

\section{Data coding and extraction strategy}

Metadata beyond that extracted for critical appraisal and outcome data (study results) will be extracted and recorded in a pre-designed datasheet. The articles included for data extraction will be split in two batches and allocated to one reviewer each. To check consistency among the two reviewers at least $25 \%$ of the articles will be double checked by the other reviewer. Data will always be recorded as reported in the primary studies. If necessary and feasible, transformations and calculations will be performed at the analysis stage. The design of the data extraction sheet and how it should be filled will be tested and approved in advance by all reviewers. We anticipate the datasheet to include the following information and parameters:

- Article citation.

- Bti treatment details (form of Bti, number of treatment years, dose/treatment, number of treatments/ year, Bti concentration in the environments (water, sediment), size of treated area).

- Study area details (country/state, location, coordinates, ecosystem type, study area size, target species, occurrence of Bti-sensitive non-target species, hydroperiod, fraction of inundated land at treatment, average water depth at treatment, habitat structure, vegetation type, water chemistry, nutrient concentrations, eutrophication index).

- Outcome details (measured outcomes or indicators of effects, unit used for outcome).

- Study results (mean, variance/standard deviation/ standard error, sample size).

- Funding body and author affiliations.

Data extraction may include contact with individual authors for complementary information or raw or unpublished data. The extracted data records will be made available in an additional file.

\section{Potential effect modifiers/reasons for heterogeneity}

Most of the treatment and study area details mentioned in the previous section are covariables that potentially can modify possible effects. However, assuming a doseresponse relationship, the dose $(\mathrm{kg} / \mathrm{ha})$ per treatment and number of treatments per year as well as the biologically active concentration in the treated system should belong to the more important effect modifiers. It has been suggested that high application rates result in higher direct impact on NTOs such as Chironomidae [10], which in turn may result in higher indirect impacts on other 
Table 4 Critical appraisal data sheet to be completed for each study when assessing study validity

\begin{tabular}{|c|c|c|}
\hline Validity domain & Parameter & Optional entries [free text if empty] \\
\hline \multirow[t]{6}{*}{ Sampling strategy } & Number of replicates & \\
\hline & Number of sampling points per replicate & \\
\hline & Scale of studied ecosystem $\left(\mathrm{m}^{2}\right)$ & $1-10 />10^{1}-10^{2} />10^{2}-10^{3} />10^{3}-10^{4} />10^{4}-10^{5} />10^{5}$ \\
\hline & Total study length (years) & \\
\hline & Follow-up period after treatments (days) & \\
\hline & Sampling frequency & \\
\hline \multirow[t]{3}{*}{ Study design details } & Study design & $\mathrm{BA} / \mathrm{Cl} / \mathrm{BACl} / \mathrm{RCT} /$ other [specify] \\
\hline & Group matching & Independent groups/matched pairs \\
\hline & Randomisation of treatment allocation & Yes/yes, within pairs/no/unclear \\
\hline \multirow[t]{3}{*}{ Selection bias } & Risk of selection bias & Low/probably low/probably high/high/unclear \\
\hline & $\begin{array}{l}\text { Appropriateness of control sites relative to treated sites based on their } \\
\text { ecological similarity }\end{array}$ & Yes/no/unclear \\
\hline & Comment on risk of selection bias & \\
\hline \multirow[t]{5}{*}{ Performance bias } & Reported or suspected confounding factor & Yes/no/unclear \\
\hline & Reported or suspected time-related trend & Yes/no/unclear \\
\hline & Reported or suspected contamination of study groups & Yes/no/unclear \\
\hline & Risk of performance bias & Low/probably low/probably high/high/unclear \\
\hline & Comment on risk of Performance bias & \\
\hline \multirow[t]{5}{*}{ Detection bias } & Differences in sampling or measuring methods between study groups & Yes/no/unclear \\
\hline & Differences in sampling timing & Yes/no/unclear \\
\hline & Differences in sampling efficiency & Yes/no/unclear \\
\hline & Risk of detection bias & Low/probably low/probably high/high/unclear \\
\hline & Comment on risk of detection bias & \\
\hline Reporting bias & All measured outcomes reported & Yes/no [specify] \\
\hline \multirow[t]{4}{*}{ External validity } & Target species & \\
\hline & Effect on target species & $\begin{array}{l}\text { Aimed effect achieved/other significant effect } \\
\text { [specify]/no significant effect/not reported }\end{array}$ \\
\hline & Dose and frequency of treatments & \\
\hline & Comment on external validity & \\
\hline
\end{tabular}

non-target organisms or ecosystem processes. Not only the application rate in itself, but also the application rate relative to the hydrological conditions plays a role. The impact at a given application rate may be different in areas with deep water compared to areas with shallower water, because the concentration and persistence of Bti in the water column will differ, as well as the community of animal species present. Another factor is the history of Bti treatments in a study area. It is not inconceivable that an ecosystem may be resilient to Bti treatments for shorter periods while repeated long-term treatments may result in larger impacts. In contrast, the pollution induced community tolerance concept [30] suggests that sensitive species go but functions are kept constant through tolerant species. In other words, species richness and species composition in the studied ecosystem may also influence the outcome. Compared to ecosystems with low biodiversity dominated by species sensitive to Bti, rich systems may be more resilient to Bti treatments if organisms directly impacted by Bti can easily be substituted by other organism (not sensitive to Bti) in food webs and ecosystem processes. If reported at all, species richness or dominance can be difficult to quantify in a unified way if different studies have used different indices for such variables. The form of Bti being applied may be another important effect modifier. In some forms the Bti crystals remain at the water surface or in the water column for a significant amount of time, whilst in other forms the crystals settle at the bottom more rapidly. This influences which species are exposed to the Bti crystals.

In summary, given that there is a sufficient number of studies and that the information is available, the following potentially effect-modifying parameters will be analysed: (1) dose/treatment, (2) number of treatments/ year, (3) biological active concentration of Bti, (4) average water depth of inundated areas, (5) duration of Bti treatment (number of years), (6) background biodiversity and community composition including non-target species sensitive to Bti cry toxins, and (7) form of Bti applied. 
This list of potential effect modifiers was compiled after consultation with stakeholders.

\section{Data synthesis and presentation}

We expect that the studies to be included in the review will range widely in terms of e.g. the environmental settings, application methods and response variables studied, and in the types of outcomes observed. Accordingly, at this stage it is unclear whether a quantitative synthesis based on meta-analysis will be feasible. Should we judge meta-analysis to be appropriate, we will apply a randomeffects model [31]. If different outcomes measured on different scales are included in the same analysis, standardised mean difference, most likely Hedge's g [32], will be used as effect size. Separate meta-analyses will be made for the two different comparators that are eligible for inclusion in the review. If quantitative meta-analysis is carried out, risk of publication bias will be assessed through funnel plots, possibly combined with Egger's test [33]. Synthesis of included studies will also be narrative. The narrative synthesis will include descriptive statistics outlining the evidence base in terms of publication year, study location, form of Bti used, target species, duration of Bti control, and studied outcome.

A narrative synthesis table in the form of an Excel spreadsheet will be provided as Additional file 4. The table will include bibliographic information including funding body and author affiliations, study characteristics, study results, risk of bias assessments, and external validity assessments. Included studies will be grouped by studied outcome, and each group will be discussed separately. Focus in the discussions will be on the strength of evidence, for which the following aspects will be considered: (1) number of studies, (2) study validity (internal and external), (3) consistency of observed effects across studies, (4) size and significance of observed effects, and (5) relationship between the intensity of the Bti treatment and the outcome (dose-response relationship). The last aspect may however not be easily evaluated since Bti is not behaving like chemicals. Bti is a bacterium having the potential to sporulate and therefore its concentration in the environment may not necessarily correlate with the amount sprayed. Finally, the overall strength of evidence, taking all included studies and outcomes into account, will be assessed.

\section{Additional files}

Additional file 1. List of organisations represented at stakeholder meeting.

Additional file 2. Evaluation of search query.
Additional file 3. Benchmark papers that should be captured in comprehensive searches.

Additional file 4. Completed ROSES form.

\section{Acknowledgements}

The preparation of this protocol and the forthcoming review is financed by Formas. The authors wish to thank three anonymous reviewers for constructive comments. We are also grateful for many valuable comments provided by Swedish stakeholders during a public review of an earlier version of this protocol.

\section{Authors' contributions}

This systematic review protocol is based on a draft written by ML. BM is the main author of the Background section. All authors discussed, edited and added text to the draft. All authors read and approved the final manuscript.

\section{Funding}

This systematic review protocol is funded by the Swedish Research Council for Environment, Agricultural Sciences and Spatial Planning (Formas). ML is employed by Formas.

\section{Availability of data and materials}

Not applicable.

Ethics approval and consent to participate

Not applicable.

\section{Consent for publication}

Not applicable.

\section{Competing interests}

The authors declare that they have no competing interests.

\section{Author details}

${ }^{1}$ The Swedish Research Council for Environment, Agricultural Sciences and Spatial Planning (Formas), Box 1206, 11182 Stockholm, Sweden. ${ }^{2}$ Institute for Environmental Sciences, University of Koblenz-Landau, Fortstrasse 7, 76829 Landau, Germany. ${ }^{3}$ The Natural Resources Institute, University of Greenwich, Medway Campus, Central Avenue, Chatham Maritime, Kent ME4 4TB, UK. ${ }^{4}$ Tour du Valat Research Institute for the Conservation of Mediterranean Wetlands, Le Sambuc, 13200 Arles, France. ${ }^{5}$ Department of Aquatic Sciences and Assessment, Swedish University of Agricultural Sciences, P.O. Box 7050, 75007 Uppsala, Sweden.

Received: 24 April 2019 Accepted: 21 July 2019

Published online: 06 September 2019

\section{References}

1. Boisvert $\mathrm{M}$, Boisvert J. Effects of Bacillus thuringiensis var. israelensis on target and nontarget organisms: a review of laboratory and field experiments. Biocontrol Sci Technol. 2000;10(5):517-61.

2. Hannay CL. Crystalline inclusions in aerobic sporeforming bacteria [10]. Nature. 1953;172(4387):1004.

3. Subbiah P, Abidha S. A medium for the production of biopesticides (Bacillus sphaericus and Bacillus thuringiensis subsp. israelensis) in mosquito control. J Econ Entomol. 2009;102(4):1423-30.

4. Boisvert M, Boisvert J, Aubin A. A new field procedure and method of analysis to evaluate the performance of Bacillus thuringiensis subsp. israelensis liquid formulations in streams and rivers. Biocontrol Sci Technol. 2001;11(2):261-71.

5. Merritt RW, Walker ED, Wilzbach MA, Cummins KW, Morgan WT. A broad evaluation of Bti for black fly (Diptera, Simuliidae) control in a Michigan river-efficacy, carry and nontarget effects on invertebrates and fish. J Am Mosq Control Assoc. 1989;5(3):397-415.

6. Schäfer ML, Lundström JO. Efficiency of Bti-based floodwater mosquito control in Sweden_four examples. J Eur Mosq Control Assoc. 2014;32:1-8 
7. Marina CF, Bond JG, Muñoz J, Valle J, Novelo-Gutiérrez R, Williams T. Efficacy and non-target impact of spinosad, Bti and temephos larvicides for control of Anopheles spp. in an endemic malaria region of southern Mexico. Parasites Vectors. 2014;7(1):55

8. Charbonneau CS, Drobney RD, Rabeni CF. Effects of Bacillus thuringiensis var. israelensis on nontarget benthic organisms in a lentic habitat and factors affecting the efficacy of the larvicide. Environ Toxicol Chem. 1994;13(2):267-79.

9. Jackson JK, Horwitz RJ, Sweeney BW. Effects of Bacillus thuringiensis israelensis on black flies and nontarget macroinvertebrates and fish in a large river. Trans Am Fish Soc. 2002;131(5):910-30.

10. Allgeier S, Kastel A, Bruhl CA. Adverse effects of mosquito control using Bacillus thuringiensis var. israelensis: reduced chironomid abundances in mesocosm, semi-field and field studies. Ecotoxicol Environ Saf. 2019;169:786-96.

11. Liber K, Schmude KL, Rau DM. Toxicity of Bacillus thuringiensis var. israelensis to chironomids in pond mesocosms. Ecotoxicology. 1998;7(6):343-54.

12. Hershey AE, Lima AR, Niemi GJ, Regal RR. Effects of Bacillus thuringiensis israelensis (Bti) and methoprene on nontarget macroinvertebrates in Minnesota wetlands. Ecol Appl. 1998;8(1):41-60.

13. Vaughan IP, Newberry C, Hall DJ, Liggett JS, Ormerod SJ. Evaluating large-scale effects of Bacillus thuringiensis var. israelensis on nonbiting midges (Chironomidae) in a eutrophic urban lake. Freshw Biol. 2008;53(10):2117-28.

14. Lajmanovich RC, Junges CM, Cabagna-Zenklusen MC, Attademo AM, Peltzer PM, Maglianese M, Maquez VE, Beccaria AJ. Toxicity of Bacillus thuringiensis var. israelensis in aqueous suspension on the South American common frog Leptodactylus latrans (Anura: Leptodactylidae) tadpoles. Environ Res. 2015;136:205-12.

15. Newman M, Clements W. Ecotoxicology-a comprehensive treatment. Boca Raton: CRC Press; 2007

16. Truchy A, Angeler DG, Sponseller RA, Johnson RK, McKie BG. Linking biodiversity, ecosystem functioning and services, and ecological resilience: towards an integrative framework for improved management. In: Woodward G, Bohan DA, editors. Ecosystem services: from biodiversity to society, Pt 1. vol. 53. 2015. p. 55-96.

17. Poulin B, Lefebvre G, Paz L. Red flag for green spray: adverse trophic effects of Bti on breeding birds. J Appl Ecol. 2010;47(4):884-9.

18. Culler LE, Ayres MP, Virginia RA. In a warmer Arctic, mosquitoes avoid increased mortality from predators by growing faster. Proc R Soc B Biol Sci. 1815;2015:282.

19. Hellgren O, Bensch S, Malmqvist B. Bird hosts, blood parasites and their vectors - associations uncovered by molecular analyses of blackfly blood meals. Mol Ecol. 2008;17(6):1605-13.

20. Schäfer ML, Lundström JO, Petersson E. Comparison of mosquito (Diptera: Culicidae) populations by wetland type and year in the lower River Dalälven region, Central Sweden, vol. 33. Bellingham: SPIE; 2008

21. Lundstrom JO, Schafer ML, Petersson E, Vinnersten TZP, Landin J, Brodin Y. Production of wetland Chironomidae (Diptera) and the effects of using
Bacillus thuringiensis israelensis for mosquito control. Bull Entomol Res. 2010;100(1):117-25.

22. Schneider S, Tajrin T, Lundstrom JO, Hendriksen NB, Melin P, Sundh I. Do multi-year applications of Bacillus thuringiensis subsp. israelensis for control of mosquito larvae affect the abundance of B-cereus group populations in riparian wetland soils? Microb Ecol. 2017;74(4):901-9.

23. Ostman O, Lundstrom JO, Vinnersten TZP. Effects of mosquito larvae removal with Bacillus thuringiensis israelensis (Bti) on natural protozoan communities. Hydrobiologia. 2008;607:231-5.

24. Vinnersten TZP, Lundstrom JO, Petersson E, Landin J. Diving beetle assemblages of flooded wetlands in relation to time, wetland type and Bti-based mosquito control. Hydrobiologia. 2009;635(1):189-203.

25. McKie BG, Taylor A, Nilsson T, Goedkoop W. Kvantifiering av ekosystemeffekter av Bti - användning i Nedre Dalälven (in Swedish). Swedish University of Agricultural Sciences. 2015. https://www.naturvardsverke t.se/upload/miljoarbete-i-samhallet/miljoarbete-i-sverige/bekampning smedel/SLU\%20Myggrapport\%200kt\%202015.pdf. Accessed 11 Feb 2019 .

26. Swedish EPA. Överlämnande av frågan om tillåtlighet enligt 7 kap. 29 § miljöbalken för bekämpning av larver av översvämningsmygg i Nedre Dalälvens översvämningsvåtmarker 2019. Ärendenr: NV-07960-18 (in Swedish). Stockholm: Naturvårdsverket; 2019.

27. Collaboration for Environmental Evidence. Guidelines and standards for evidence synthesis in environmental management. Version 5.0. In: Pullin AS, Frampton GK, Livoreil B, Petrokofsky G, editors. 2018.http://www.envir onmentalevidence.org/information-for-authors. Accessed 11 Feb 2019.

28. Harzing AW. Publish or Perish. 2007. https://harzing.com/resources/publi sh-or-perish.

29. Swedish EPA. Omprövning gällande ansökan om Natura 2000-tillstånd samt dispens från förbudet att sprida biocidprodukter från luftfartyg för bekämpning av larver av översvämningsmygg under 2018 i översvämningsområden vid Nedre Dalälven. Ärendenr: NV-07545-17 (in Swedish). Stockholm: Naturvårdsverket; 2018.

30. Blanck H, Wängberg S-A, Morlander S. Pollution-induced community tolerance-a new ecotoxicological tool. In: Cairns J, Pratt JR, editors. Functional testing of aquatic biota for estimating hazards of chemicals. Philadelphia: American Society for Testing and Materials; 1988. p. 219-30.

31. Borenstein M, Hedges LV, Higgins JPT, Rothstein HR. Introduction to meta-analysis. Chichester: Wiley; 2009.

32. Hedges LV. Distribution theory for glass's estimator of effect size and related estimators. J Educ Stat. 1981;6(2):107-28.

33. Egger M, Smith GD, Schneider M, Minder C. Bias in meta-analysis detected by a simple, graphical test. BMJ. 1997;315(7109):629-34.

\section{Publisher's Note}

Springer Nature remains neutral with regard to jurisdictional claims in published maps and institutional affiliations.
Ready to submit your research? Choose BMC and benefit from:

- fast, convenient online submission

- thorough peer review by experienced researchers in your field

- rapid publication on acceptance

- support for research data, including large and complex data types

- gold Open Access which fosters wider collaboration and increased citations

- maximum visibility for your research: over 100M website views per year

At $\mathrm{BMC}$, research is always in progress.

Learn more biomedcentral.com/submissions 